\title{
RELIGIOSIDAD FEMENINA Y EDUCACIÓN DE LA MUJER INDÍGENA EN FILIPINAS. EL BEATERIO-COLEGIO DE LA MADRE PAULA DE LA SANTÍSIMA TRINIDAD
}

POR

\author{
MARTA M. MANCHADO LÓPEZ \\ Universidad de Córdoba
}

\begin{abstract}
En este trabajo se estudia la historia del beaterio de Santa Rosa, o de la madre Paula, desde su fundación en 1750 y hasta su definitiva consolidación, en 1789. A lo largo de estos treinta y nueve años, el centro, nacido de la generosidad de una española, hizo frente a importantes dificultades hasta conseguir finalmente el apoyo real y el reconocimiento de la ciudad de Manila.

El estudio se ha realizado sobre documentación inédita del Archivo General de Indias de Sevilla, y supone una aportación al conocimiento de la naturaleza y funcionamiento de estas comunidades, cuya historia está aún por hacer.
\end{abstract}

\section{INTRODUCCIÓN}

En el siglo XVIII existían en Filipinas varios centros de enseñanza dedicados a la formación de niñas. La mayor parte, en realidad, tenían una doble naturaleza, ya que eran casas de enseñanza y también centros en los que vivían retiradas mujeres devotas. Recibían el nombre de beaterios y estaban en conexión con alguna orden religiosa que los tutelaba. Era frecuente que se profesaran votos, aunque no siempre sucedía así.

Esta doble función determina el que con frecuencia se les designe con los términos «colegio», «casa de enseñanza» o «beaterio» indistintamente. Por otro lado, era frecuente que las beatas ejercieran 
el oficio de maestras de las niñas, lo que explica la doble función de estos centros ${ }^{1}$.

Entre ellos destacan el beaterio de Santa Catalina de Sena, el de San Ignacio o de la Compañía, el de San Sebastián de Galumpang, el de Santa Rita de Pasig y el de Santa Rosa o de la madre Paula ${ }^{2}$.

Tal y como afirma el Profesor Borges Morán, la historia de este sistema de vida religiosa está aún por hacer. Su estudio entraña serias dificultades, nacidas sobre todo del carácter «autonómico y aislado» de los beaterios. Su frecuente evolución hasta convertirse en conventos y la proyección social que en ocasiones alcanzaron, a través de labores de beneficencia y enseñanza, contribuyen a hacer más complejo su estudio ${ }^{3}$.

El presente trabajo está dedicado al beaterio de la madre Paula, desde su fundación en 1750 y hasta su definitiva consolidación, en 1789. A lo largo de estos treinta y nueve años este centro, nacido de la generosidad de una española, hizo frente a importantes dificultades hasta conseguir finalmente el apoyo real y el reconocimiento de la ciudad de Manila.

1 Este parece haber sido también el caso del recogimiento fundado en México por doña Catalina de Bustamente con el apoyo del virrey don Antonio de Mendoza y del arzobispo fray Juan de Zumárraga. En él se impartía enseñanza a las niñas indígenas y, aunque fracasó, queda como el primer intento de instrucción de la mujer indígena mexicana. Véase E. LUQUE ALCAIDE, La educación en Nueva España en el siglo XVIII, Sevilla, 1970, pp. 279-298.

El presente trabajo se ha enriquecido con las indicaciones bibliográficas que me ha aportado la profesora Justina Sarabia Viejo, cuya amabilidad agradezco desde estas páginas.

2 M. BuZETA y F. BRAvo Diccionario geográfico, estadístico, histórico de las islas Filipinas, Madrid, 1850, 2 vols. Existían además dos colegios: el de Santa Isabel, fundado en 1632 por la Hermandad de la Misericordia y dedicado a la educación de hijas de españoles, y el de Santa Potenciana, creado en el siglo XVI para hijas de los soldados españoles distinguidos. Sobre este último, véase M. L. DiAZ-TrECHUElO, Arquitectura española en Filipinas (1565-1800), Sevilla, 1959, pp. 241-245. En opinión de Angel MARTINEZ CUESTA, el centro creado por la madre Paula fue un simple colegio. Véase «Monjas y beatas en Filipinas, 1621-1898», en I Congreso Internacional del monacato femenino en España, Portugal y América, 1492-1992, T.I, León, 1993, p. 520, nota 9. El carácter mixto que tuvo este centro, como casa de recogimiento y de enseñanza, y la voluntad de la propia fundadora, patente en su testamento, así como toda la documentación relativa a esta obra, nos permite, sin embargo, aplicarle el término de «beaterio» que, como queda dicho, es una fundación de perfiles poco nítidos.

3 P. BORGES MORAN Religiosos en Hispanoamérica, Madrid, 1992, cap. IX, «La vida religiosa no institucionalizada», pp. 307-312.

R. I., $1999, \mathrm{n}^{\circ} 215$ 


\section{LA CREACION DEL BEATERIO}

El beaterio fue constituído por la madre Paula de la Santísima Trinidad en Manila, en el año 1750 (un año después de su llegada a las islas) con el objeto de ser casa de recogimiento y de enseñanza de niñas y jóvenes pobres, tanto indias como de otras castas ${ }^{4}$.

Según consta en los documentos, la creación de este beaterio se hizo sin obtener previa autorización real, la cual se intentó conseguir una vez que éste ya se había levantado ${ }^{5}$. Es entonces cuando se plantea por parte de la Corona la polémica sobre la utilidad de dicho centro y la conveniencia o no de que subsistiera, habida cuenta de la existencia de otras instituciones similares en Manila. Efectivamente, recibidas en la corte las primeras noticias sobre el beaterio, se libraron sendas Reales Cédulas al arzobispo y a la Audiencia de las islas pidiéndole informes sobre el asunto ${ }^{6}$.

La opinión del metropolitano fue muy favorable a la casa de recogimiento y enseñanza en la que recibían instrucción ciento ochenta niñas en la doctrina cristiana, lengua castellana y los oficios propios de su sexo. Todo ello bajo la dirección de la madre Paula, cuya diligencia en la consecución de limosnas, tanto en las islas como en Nueva España, permitían mantener a las niñas que educaba «con suficientes alimentos y amplitud de habitación»7.

Además, el arzobispo, conocedor de la vida ejemplar de la madre Paula y de su capacidad para llevar adelante su empeño, le había

4 Según consta en su testamento, la madre Paula era natural del pueblo de Apluxacalva, obispado de Tarragona, e hija legítima y de legítimo matrimonio de don José Tegidor y doña Teresa del Mao. Testimonio del testamento de la madre Paula, AGI, Filipinas, 652. De ella nos dice el Padre Fernández que era «devotísima de Nuestro Padre, del Rosario y del Santísimo Sacramento, muy dada a toda clase de mortificaciones y penitencias, notable educadora de la juventud femenina». FERNANDEZ, P. Dominicos donde nace el sol, Barcelona, 1958, pp.340-341. Véase también sobre la madre Paula, J. FERRANDO, Historia de los padres dominicos en las islas Filipinas y en sus misiones del Japón, China, Tung-kin y Formosa, Madrid, 1871, vol.V, pp. 244-247.

5 Dictamen del Fiscal de Consejo de Indias, Madrid, 26 de junio de 1784, AGI, Filipinas, 652. El beaterio era de la observancia de la orden tercera de Santo Domingo.

6 La Real Cédula está fechada en 23 de noviembre de 1766. Era entonces arzobispo de Manila el escolapio aragonés Basilio Sancho de Santa Justa y Rufina quien, con licencia especial, había sido consagrado el 18 de agosto de 1766 en Madrid, no llegando a tomar posesión de su mitra hasta su arribo a las islas en julio del siguiente año.

$7 \mathrm{El}$ arzobispo remitió los informes pedidos en carta de 1 de agosto de 1768. Su contenido está extractado en el texto de la Real Cédula dirigida a la Audiencia de Manila y fechada en Madrid a 2 de julio de 1773, AGI, Filipinas, 652. 
dado licencia para disponer de un oratorio. Seguro, por otra parte, de que esta obra daba cumplimiento a las leyes sobre conservación y fundación de casas para la educación de las indias.

Los informes de la Audiencia de las islas, tras la preceptiva inspección, también resultaron positivos, aunque se dejó notar la existencia de cierta confusión en la inversión de las limosnas recibidas. Asimismo, se acordó el nombramiento anual de un ministro de la Audiencia para que visitase la casa, como fundación sujeta al Real Patronato. En definitiva, en opinión de la Audiencia, la casa de recogimiento de la madre Paula podía mantenerse, pero sólamente hasta el fallecimiento de la fundadora, momento en que debía decidirse si había una persona cualificada para continuar la obra, o era preferible unirla al beaterio de Santa Catalina. La existencia de un número suficiente, e incluso excesivo, de casas de recogimiento hacía temer que, desaparecida la madre Paula, acabaran también las donaciones piadosas que mantenían su obra en pié.

El tema del beaterio volvió a plantearse a raíz de la solicitud de su fundadora para que se le concediera la hacienda de Maygaringue, que había sido de los jesuitas, con el fin de beneficiarse de sus rentas. El informe del Fiscal del Consejo fue drástico, en el sentido de que el mantenimiento del beaterio podía generar importantes conflictos, además de perjudicar a los colegios y recogimientos ya existentes, al hospital de San Juan de Dios, y a las órdenes religiosas. Efectivamente, al obligar a repartir las limosnas de los ciudadanos de Manila se vería reducido el porcentaje que cada uno percibía, poniéndose en peligro algunas obras pías. Tal era el caso del citado hospital, que mantenía a más de cien pacientes. Por otro lado, el Fiscal también afirma que

«las niñas indias se crían y educan más bien al lado de sus madres y parientas, porque para coser y toda labor de aguja lo hacen mucho mejor las indias que la expresa hermana Paula, y para aprender la lengua castellana no necesitan de otra cosa más que el trato con españoles» ${ }^{8}$.

En cualquier caso, la decisión final dependería de los informes del gobernador de las islas, quien debía valorar la cualificación de

8 Vista del Fiscal del Consejo de Indias, incluída en el texto de la Real Cédula, Madrid, 2 de julio de 1773, AGI, Filipinas, 652.

R. I., $1999, \mathrm{n}^{\circ} 215$ 
las mujeres más instruídas del beaterio, a fin de confiarles su dirección, o resolver su integración en el beaterio de Santa Catalina, manteniendo, eso sí, el régimen de vida aprobado para el extinto beaterio. Cabía otra posibilidad, y era la supresión total de la casa de recogimiento de la madre Paula, pero en caso de adoptarse esta resolución, el Fiscal señala que debía realizarse necesariamente con el acuerdo de la Audiencia, a fin de evitar la intromisión de la jurisdicción eclesiástica en este asunto.

El informe del Fiscal deja clara su frontal oposición a la continuación de una obra a la que tacha abiertamente de innecesaria y perjudicial. Pero no se detiene aquí, sino que vaticina que su conservación sería fuente constante de problemas en materia jurisdiccional, al enfrentar al gobernador, en su calidad de vicepatrón, con las autoridades eclesiásticas. Efectivamente, asegura que ya se le había concedido oratorio propio donde recibían la comunión, y que pronto aspirarían a tener iglesia pública y a profesar los tres votos y el de clausura perpetua 9 .

La resolución real en este asunto quedó aplazada, en tanto se recibían nuevos informes de las islas. De esta forma, se expidió la Real Cédula de 2 de julio de 1773 por la que se disponía el mantenimiento de la casa de recogimiento en el ser que tenía, prohibiéndose expresamente que aumentara el número de niñas recogidas.

\section{ÓRDENES RELIGIOSAS Y OBRAS PÍAS. LA GENEROSIDAD DE LA SOCIEDAD DE MANILA.}

La Real Cédula fue recibida en las islas en agosto del siguiente año. El fiscal de la Audiencia pidió que se ordenara a la madre Paula la redacción de una lista en que constaran los nombres de las niñas recogidas, a fin de que, en caso de quedar alguna vacante, no se pu-

9 Este había sido el proceso seguido por el beaterio de Santa Catalina, que comenzó como casa de enseñanza con un legado de un vecino de Manila para que un máximo de doce mujeres «de edad y prudencia» cuidaran y educaran niñas españolas. Andando el tiempo, la habilidad e insistencia de los padres dominicos consiguieron iglesia pública y campana, y aunque no obtuvieron permiso para profesar los votos y la clausura, los establecieron. Esto despertó las suspicacias de los franciscanos que temían que este beaterio les privara de muchas de las limosnas que necesitaban para el mantenimiento de su convento y del de Santa Clara. 
diera incorporar otra en su lugar. Además, consideró necesario pedir informes sobre el monto real de las limosnas que recibían todas las órdenes religiosas de las islas y si eran suficientes para su propio mantenimiento y el de las obras pías que dependían de ellas. Lo mismo habría de preguntarse a la madre Paula, y al proveedor y diputados de la Casa de la Santa Misericordia ${ }^{10}$. También era importante conocer la capacidad real de la sociedad manilense para sostener tantas obras pías, y para ello se solicitó informe al cabildo de la ciudad, y al Consulado ${ }^{11}$.

Todos los informes fueron incorporados al expediente relativo al beaterio de la madre Paula, y a través de ellos podemos conocer la situación en que se encontraban los conventos de la capital y las obras pías sostenidas por la generosidad de los habitantes de Manila, fuertemente condicionada por la evolución del comercio con Acapulco.

En cuanto a la situación de los conventos, todos los informes denuncian que se encontraban en condiciones similares, carentes de recursos suficientes y subsistiendo con grandes dificultades. Así, por ejemplo, el provincial de San Gregorio Magno, fray Francisco Antonio Maseyra, informó de que su provincia carecía de bienes temporales, debido a la regla que profesaba, y, aunque no disponía de los libros de cuentas del convento en el momento de hacer el informe, sabía «por haber sido prelado de la comunidad de Manila», que era imposible mantenerla con decencia sin el recurso de las limosnas procedentes del sobrante de algunos pocos ministerios grandes que administraban los franciscanos, y aquellas otras que voluntariamente remitían los doctrineros en plata o en especie ${ }^{12}$. Los ingresos mensuales del convento provenientes de las limosnas suponían unos 40 pesos aproximadamente, cantidad que no alcanzaba para comprar el

10 La Casa de la Misericordia de Manila tiene sus orígenes en la generosidad del presbítero Juan Fernández de León, llegado a las Filipinas en 1591. Sobre su historia y características véase el trabajo de la profesora M. L. DiAz-TRECHUELO, «La Casa de la Misericordia de Manila», presentado en el XI Congreso del Instituto Internacional de Historia del Derecho Indiano, celebrado en Buenos Aires en septiembre de 1995. Actualmente se encuentra en prensa, lo he podido consultar gracias a la gentileza de su autora, que agradezco desde estas páginas.

11 Vista del Fiscal de la Audiencia, Manila, 26 de agosto de 1774. Esta petición fue aprobada por el Real Acuerdo de 29 de agosto. Ambos documentos en AGI, Filipinas, 652.

12 Informe de fray Francisco Antonio Maseyra, provincial de franciscanos, Maoban, 4 de abril de 1775. El real auto por el que se ordenaba la redacción de este informe fue notificado el 9 de marzo del mismo año al guardián del convento de Nuestra Señora de los Angeles de Manila, fray Santiago de la Cabeza, AGI, Filipinas, 652.

R. I., $1999, \mathrm{n}^{\circ} 215$ 
pan y la carne necesarios para el sustento de los religiosos. A estas se sumaban otras limosnas que dependían del resultado de la feria del puerto de Acapulco y del estado de la república «que al presente es deplorable».

Contaba la orden también con algunas limosnas procedentes de obras pías creadas por la orden tercera y por la Casa de la Misericordia, pero que se habían reducido tanto que no alcanzaban a la mitad de la cantidad en que se fundaron, «ni es fácil se recobren en breve, ni recobradas es fácil derramen con la abundancia que quisieron sus fundadores» ${ }^{13}$.

Por lo que respectaba al Real Monasterio de Santa Clara, este recibía unos seis pesos al mes aproximadamente, lo que resultaba insuficiente para acometer las necesarias obras de reparación de la iglesia.

En cuanto a los recoletos, su provincial reconoce que el convento de Manila no podía mantenerse a expensas del vecindario de la ciudad. Recibía mensualmente entre tres y cuatro pesos procedentes de limosnas libres, y entre quince y veinte pesos de limosnas de misas, excepción hecha de los meses en que se rezaba alguna novena y se hacían colectas especiales, alcanzándose entonces la cifra de unos cuarenta o cincuenta pesos. De cualquier forma, estas cantidades eran notablemente insuficientes para hacer frente a los gastos de mantenimiento del convento cuantificados en unos ciento sesenta o ciento setenta pesos, «aun ahora que es cortísima en el número la comunidad, pues no son más que dieciocho los religiosos de ella» ${ }^{14}$.

El informe del prior del convento de Santo Domingo, fray Carlos Masvidal, es el más detallado de todos, ya que reproduce las cuentas del año anterior tal y como constaban en los libros del convento, desglosando mensualmente los ingresos y señalando cuidadosamente su procedencia. El total ingresado por limosnas de misas, cera, alhajas y adornos para altares, y otras donaciones de diversa índole asciende a 5.985 pesos y 6 granos $^{15}$.

13 Ibidem.

14 Informe del provincial de recoletos, fray Roque de San Bruno, San Sebastián, 20 de marzo de 1775. La notificación del real auto tuvo lugar en el mismo pueblo extramuros de Manila, el día 11 del mismo mes. AGI, Filipinas, 652.

15 Certificado de las cuentas del convento de los dominicos de Manila, año 1774, firmado por fray Carlos Masvidal, prior de dicho convento y comisario del Santo Oficio, Manila, 23 de marzo de 1775, AGI, Filipinas, 652. Entre la documentación estudiada no se incluye el informe correspondiente a los agustinos calzados. 
Por su parte, el beaterio de Santa Catalina, vinculado a los dominicos, contaba en el año 1775 con diez maestras y veintinueve niñas. De éstas últimas sólo cuatro pagaban sus alimentos, mientras que las veinticinco restantes eran mantenidas y alimentadas por el beaterio $^{16}$. Sin embargo, esta no era la única casa de recogimiento con que contaba la ciudad, existía otra conocida como beaterio de la Compañía de Jesús en el que vivían unas noventa y cuatro mujeres. La situación económica de este también era difícil, ya que las limosnas no alcanzaban ni siquiera para garantizar su sustento. Completaban sus ingresos con lo obtenido del lavado de ropa, de la costura, y de la preparación de cigarros «que se doblan y se venden en este beaterio»17.

Con todo, su situación económica era bastante precaria, encontrándose con frecuencia empeñado. Según los datos extraídos de los libros de cuentas que la priora relaciona, el ingreso principal del beaterio procedía de las cantidades entregadas en concepto de pupilaje, y que para el quinquenio 1769-1773 supusieron unos 3.765 pesos aproximadamente. A esta cantidad seguían los ingresos procedentes de los trabajos realizados en el beaterio, unos 1.125 pesos. Un monto más reducido alcanzaban las limosnas entregadas por bienhechores, en torno a los 604 pesos para el periodo señalado ${ }^{18}$.

Por lo que respecta al único hospital con que contaba la ciudad de Manila, atendido por los hermanos de San Juan de Dios, contamos con los informes redactados por su prior, y por el secretario de

16 Informe de la priora del beaterio de Santa Catalina, sor Josefa de la Asunción, Manila, 26 de marzo de 1775. Este informe fue redactado en cumplimiento de la orden de 18 de marzo del mismo año firmada por el vicario provincial de Santo Domingo, fray Joaquín del Rosario. Este beaterio fue fundado en 1696 por la madre Francisca del Espíritu Santo, natural de Manila, y por el padre fray Juan de Santo Domingo, provincial de la orden de predicadores. Además de recogimiento de mujeres devotas, tenía como objeto la formación de jóvenes españolas. M. BuZETA, y F. BRAVo, [2]. T.I, p.164. Sobre este beaterio, véase el estudio de Carlos Alvarez Nogal, «El beaterio de Santa Catalina en Manila», en I Congreso Internacional del monacato femenino en España, Portugal y América, 1492-1992, T.I. León, 1993, pp. 521-529.

17 Razón individual de los ingresos del beaterio de la Compañía, años de 1769 a 1773, firmado por su priora Úrsula del Rosario, Manila, 26 de abril de 1775. AGI, Filipinas, 652. Este beaterio, que fue fundado en 1799 bajo la dirección de los padres jesuitas, tras su expulsión pasó a depender del provisor del arzobispado.

18 «Razón individual de las limosnas, así en plata como en especie, de lo que producen las lavadas, costuras y cigarros que se doblan y se venden en este beaterio, computándose un año con otro por un quinquenio», datos tomados del libro de asiento del beaterio de la Compañía. Manila, 26 de abril de 1775, AGI, Filipinas, 652. Sobre las limosnas entregadas en especie, véase el apéndice.

R. I., $1999, \mathrm{n}^{\circ} 215$ 
la Real Mesa de la Santa Misericordia. Ambos son prolijos y contienen datos de gran interés sobre esta institución, sobre el desarrollo de su labor asistencial y sobre las grandes dificultades a que debía hacer frente, derivadas de unas finanzas notablemente insuficientes.

El prior del citado hospital presentó una relación detallada del número de enfermos asistidos, ciento treinta o ciento cuarenta, distinguiéndose entre los atendidos en catres (sesenta), y los que se encontraban en el suelo (entre setenta y ochenta). A éstos había que sumar los que eran asistidos de pie en la portería. Con todo, este número no era estable, ya que, como señala dicho padre

«en tiempos catarrales y de epidemias es el número mucho más excesivo, como en las de las viruelas el año de 1761, que todos los días llegaban a más de doscientos los contagiados en este hospital (sin los muchos que con repetición notable eran traídos para sólo morir y ser por su pobreza enterrados), por ser, como es notorio y público, el único que hay en esta ciudad para todos estados, sexos y calidades» ${ }^{19}$.

Las necesidades del hospital (ropas, utensilios de enfermería, salario del cirujano y sirvientes, gastos para el culto divino, ropa de los religiosos y esclavos...) se cubrían en la medida de lo posible a través de una administración rigurosa y eficaz, aunque no se podía evitar pasar escaseces. Los gastos alcanzaban los 4.628 pesos, 3 reales y 7 granos al año, cantidad ésta que no incluía los gastos de botica y de reparación del convento, iglesia y enfermería. Estas obras no habían sido completas, ya que no se había podido acometer la reparación del tejado de la iglesia que amenazaba ruina, y tampoco de la bóveda, que se encontraba también en muy mal estado. Las cantidades requeridas para estos trabajos eran muy grandes y se carecía de fondos para ello.

Los ingresos con que contaba el hospital procedían fundamentalmente de limosnas recogidas en la ciudad y sus extramuros de los vecinos. Estos, eclesiásticos y seculares con título de hermanos de la orden, aportaban seis pesos anuales para ayuda de la comida de los enfermos el día de su devoción que tenían señalado, siempre, claro

19 Informe de fray José de Mendoza, prior del convento hospital de la ciudad de Manila, notario del Santo Oficio y vicario provincial de la orden de San Juan de Dios en las islas, Convento de San Juan de Dios, Manila, 6 de abril de 1775, AGI, Filipinas, 652. Este hospital fue fundado en 1596 por la Hermandad de la Santa Misericordia. 
está, que pudieran afrontar este gasto, ya que no era infrecuente que se alegara la imposibilidad de contribuir con la limosna establecida. Otros ingresos procedían de limosnas ocasionales y de las obras pías de la Mesa de la Misericordia, de la orden tercera de San Francisco y de la catedral. Así, en el año 1772 se habían recogido 2.137 pesos, 4 reales y 7 granos. ${ }^{20} \mathrm{El}$ año siguiente se dispuso de 1.661 pesos, 2 reales y 2 granos, y el de 1774 se consiguieron 3.137 pesos, 3 reales y 8 granos. En definitiva, se venían a recaudar una media de 2.331 pesos al año aproximadamente procedentes de las limosnas. A esta cantidad se añadía el fruto de pequeñas fincas, de misas, mortajas y entierros, y las gratificaciones que los religiosos recibían por algunas sangrías, curas y asistencias a enfermos fuera del hospital. El total de lo recaudado en estos tres años ascendía a 16.070 pesos y 3 reales, cantidad claramente insuficiente para cubrir las necesidades del hospital. A esto se sumaba el hecho de que no se trataba de ingresos fijos, sino que oscilaban de un año a otro,

«y que en ocasiones varían con notable decadencia por falta de limosnas y otros accidentes que precisan a la solicitud de suplementos y a los más apurados arbitrios de pedir y mendigar, y de que por estos motivos, por cumplir con el instituto, se halle el convento empeñado en cantidades crecidas de pesos, hasta empeñar y quedar vendidas las alhajas de plata de su iglesia»21.

Así pues, no se disponía de recursos suficientes para hacer frente a los cerca de 5.000 pesos de gastos regulares del hospital, a los que debían sumarse los gastos de botica (que alcanzaban los 2.545 pesos) y los derivados de las necesarias obras de reparación de los edificios. Por lo que respecta a la botica, gracias a una administración muy cuidadosa se disponía de los medicamentos más precisos, pero

20 De esta cantidad correspondían 160 pesos, 3 reales y 11 granos a las limosnas recogidas en la ciudad; 251 pesos y 2 reales a las limosnas de las hermandades; 576 pesos y 6 reales a limosnas sueltas; 801 pesos, 7 reales y 4 granos a la Casa de la Misericordia; 118 pesos, 4 reales y 3 granos a lo aportado por la orden tercera, y 285 pesos, 5 reales y 1 grano a la catedral. En el año siguiente no hubo nada de la orden tercera ni de la catedral. Informe de fray José de Mendoza, prior del convento hospital de San Juan de Dios de Manila, Manila, 6 de abril de 1775. AGI, Filipinas, 652.

21 Ibidem. Véase en el apéndice la relación de limosnas en especie recibidas en el hospital entre 1772 y 1774 .

R. I., $1999, \mathrm{n}^{\circ} 215$ 
no se encontraba bien abastecida. En cuanto al personal del hospital, también era el imprescindible y sus salarios reducidos.

La situación del hospital de Cavite no era mejor, aunque atendía a menos enfermos. Efectivamente, tenía unos diez enfermos varones diarios, y a los gastos generados por su asistencia se debía sumar el costo de dos o tres religiosos para su cuidado. Con todo, su situación era angustiosa porque, como asegura el prior del convento de Manila: «ha pendido su conservación de la actividad, celo y aplicación de los prelados que lo han gobernado, y padece las escaseces que da de sí aquel puerto». Además, no había sido cumplida la real cédula de 30 de octubre de 1766, por la que se ordenaba al gobierno de las islas arbitrara los medios necesarios para librar al hospital de las deudas que había contraído, y asegurar en el futuro rentas que permitieran el mantenimiento desahogado de tan necesaria obra.

La documentación analizada nos permite ver cómo las limosnas aportadas por los vecinos de Manila eran notablemente insuficientes para garantizar el mantenimiento de los conventos y las obras pías, pero también deja claro que era un recurso al que no se podía renunciar. El problema que se planteaba entonces era el de la distribución de los ingresos derivados de la generosidad de la sociedad manilense, y en este punto todos coinciden en que la situación económica era muy difícil y que el establecimiento de una nueva casa de recogimiento resultaba perjudicial porque forzaba a un reparto mayor de las limosnas. Esta es la opinión de la ciudad de Manila, que «halla que no puede concurrir el vecindario con asistencia de limosnas a más casas de comunidad que las que ya tiene esta capital». La razón aducida era «el deplorable estado a que se halla reducido el vecindario de esta capital, ya por la inmediata pasada guerra, ya por las posteriores arribadas de los navíos despachados por el comercio al puerto de Acapulco, y subsecuentemente los quebrantos que han padecido, causados por las malas ferias» ${ }^{22}$.

Esta misma opinión mantiene el Real Tribunal del Consulado quien insiste en el lamentable estado del comercio y en las negras perspectivas para el futuro:

22 Informe de la Ciudad de Manila, Sala del despacho de Manila, 28 de marzo de 1775, AGI, Filipinas, 652. El documento aparece firmado por D. Diego García Herreros, D. Alberto Jacinto de Reyes, D. Antonio Díaz Conde, D. Pedro Antonio Pérez de Tagle, D. Felipe Vélez Escalante y D. José Casal Bermúdez y Alvarado. 
«Hablando por lo general, parece que el estado del comercio se halla tan deplorable, $\tan$ en los últimos, con tan remotas esperanzas de su adelantamiento, con tan seguros temores de su mayor atraso, que por grande que sea la caridad de sus comerciantes, no podrán sin notable quebranto de su giro, dar aquellas asistencias y limosnas que antes daban a las comunidades religiosas que se mantienen de ellas» ${ }^{23}$.

Entre todas se destacaba por su utilidad y necesidad la de San Juan de Dios, pero ni aun a esta se podía socorrer con las cantidades con que se había hecho en otros tiempos. De esta forma, la decadencia del comercio había repercutido negativamente en la asistencia dada a los enfermos llegándose a dar el caso de que «a veces los frailes para el sustento de los enfermos se quitan el bocado de la boca». Esta era la situación general que vivía el comercio en las islas y la razón de la disminución de las limosnas a órdenes religiosas y obras pías, pero una cosa era el estado del comercio y otra la cantidad que cada comerciante podía entregar, llevado de la caridad y según su particular situación familiar y económica. Así, el Tribunal del Consulado insiste en que en este punto no puede decir nada, y que todo pende de la voluntad individual.

«Pues habrá individuo a quien no redituándole su comercio más que tres o cuatro mil pesos, podrá y tendrá ánimo para distribuir uno o dos mil, y habrá a quien le reditúe mucho más que no pueda ni tenga valor para dar siquiera diez pesos de limosna. Porque el primero puede tener una grande caridad, ningunas responsabilidades en el desperdicio o distribución de su caudal, tener espera en otras pretensiones, de suerte que aunque se le acabe el caudal, no por eso se expondrá a perecer ni mendigar, y no tener familia alguna, y lo contrario le sucederá al segundo» ${ }^{24}$.

23 Informe del Real Tribunal del Consulado de Manila, Sala del Despacho del Real Tribunal del Consulado de Manila, 29 de abril de 1775, AGI, Filipinas, 652. Ciertamente, el comercio había experimentado una contracción a causa del cierre del puerto de Manila para los buques europeos, medida adoptada tras la guerra con los ingleses. Este periodo de decadencia comprende los años 1762 a 1785 , momento en que se reanuda el tráfico comercial, al entrar en el puerto numerosos barcos europeos amparados por pabellones asiáticos. Véase M. L. DiAz-TreChuelo, «Historia económica de Filipinas en la segunda mitad del siglo XVIII», Cuadernos del Centro Cultural, 5, Manila, 1978, pp.31-38.

24 Informe del Real Tribunal del Consulado de Manila, Sala del Despacho del Real Tribunal del Consulado de Manila, 29 de abril de 1775, AGI, Filipinas, 652.

R. I., $1999, \mathrm{n}^{\circ} 215$ 


\section{LA POSTURA DE LA AUDIENCIA DE MANILA}

Pasada toda la documentación a manos del oidor fiscal de la Audiencia, éste emitió un extenso informe totalmente contrario a las pretensiones de la madre Paula. Las razones aducidas son variadas, pero fundamentalmente «la ninguna pública utilidad» derivada de la casa de recogimiento y enseñanza citada al existir en las islas un número suficiente de casas de educación para todo género de personas. Además, el oidor fiscal insiste en que la falta de medios para su subsistencia hacía segura su desaparición, una vez fallecida la fundadora. Entre tanto, las limosnas que recogía sin licencia para ello, de los vecinos de Manila, iban en detrimento de las órdenes religiosas cuyos ingresos se reducían. A todo ello venía a sumarse la mala situación del comercio con Acapulco y los informes desfavorables de las órdenes religiosas y de las instituciones consultadas.

Tan sólo el arzobispo se había manifestado a favor del beaterio, al que había concedido oratorio y clausura. Las razones que le habían llevado a apoyar dicha obra se le escapaban al oidor fiscal, quien también señala irregularidades en el funcionamiento y normas del beaterio. Así, por ejemplo, tanto el metropolitano como el provisor, habían recluído allí en muchas ocasiones a mujeres «bien relajadas», cuyo contacto con las niñas educandas era a todas luces peligroso. Por otro lado, era costumbre impuesta por la madre Paula el cortar el cabello a las jóvenes recogidas, siendo así que esto contravenía abiertamente lo dispuesto por las leyes en materia de castigos a los indios ${ }^{25}$.

En definitiva, el oidor fiscal no era partidario del mantenimiento de la casa de recogimiento, pero, en caso de permitirse su conservación, ésta sólo debía subsistir en tanto viviera su fundadora, siendo en tal caso inexcusable proceder a una reforma. Era preciso que se suprimiera la práctica de recluir en ellas a mujeres incontinentes. Asimismo, el gobernador debía nombrar un ministro encargado de visitar la casa y de poner en libertad a las jóvenes que no estuvieran

25 Este castigo estaba reservado a las mujeres públicas. De esta forma, la afrenta inferida a las jóvenes recogidas en el beaterio para recibir instrucción era, a juicio del oidor fiscal, una injustificable ofensa y violación de las leyes. Sobre el empleo de los beaterios como casas de reclusión de mujeres, véase el trabajo de $\mathbf{M}^{a}$ Isabel VIFORCOS MARINAS, «Los recogimientos, de centros de integración social a cárceles privadas: Santa Marta de Quito», Anuario de Estudios Americanos, T.L-2, Sevilla, 1993, pp. 59-92. 
por propia voluntad en ella. Se debía comunicar al arzobispo la conveniencia de que las educandas acudieran a misa a la catedral, y no se debía permitir contravenir la orden real relativa al número de jóvenes recogidas, el cual no debía aumentar bajo ningún pretexto. Tampoco se debía prohibir a ninguna de ellas abandonar el beaterio para tomar estado, o para regresar a casa de sus padres o parientes.

La propuesta de unir la casa de la hermana Paula a alguno de los beaterios existentes fue desestimada por el fiscal, quien entendió que los bienes de la fundación de la hermana Paula debían pasar, tras su muerte, al hospital de San Juan de Dios ${ }^{26}$.

La opinión del oidor fiscal no fue compartida por los miembros de la Audiencia que presentaron sus votos particulares sobre el asunto. Partidario decidido de la obra de la madre Paula era don Juan Francisco de Anda. Este aseguraba que era un medio utilísimo para educar a las mujeres indígenas quienes, andando el tiempo, podían trabajar como maestras en los pueblos. De esta forma se acabaría con la presencia de mujeres en las calles y se daría cumplimiento a las disposiciones reales sobre enseñanza del castellano a los naturales.

También don Félix Quijada y Ovejero defendía la conveniencia de que persistiera el beaterio. Pondera los beneficios de dicha obra, merecedora de ser fomentada, proponiéndola como modelo para la creación de una casa semejante para hombres «para que se librase esta república de tantos ladrones y vagabundos». Además, la muerte de la fundadora no tenía por qué conllevar la desaparición del beaterio, habida cuenta de que quedaban otras mujeres lo suficientemente capaces para continuarla.

Don Juan Antonio de Uruñuela por su parte, consideraba que una vez fallecida la fundadora, se debía proceder al traslado de las niñas educandas al beaterio de la Compañía, o al de Santa Catalina, agregándose también los bienes de que gozara el beaterio extinto. De esta manera, se daría cumplimiento a las últimas disposiciones reales sobre creación de casas de enseñanza para indias, puesto que sólo sería menester ampliar el beaterio de Santa Catalina. Esto supondría un ahorro, ya que siempre era más costoso la erección de un colegio de nueva planta que el aprovechamiento de un centro ya existente, y permitiría librar fondos para una obra realmente necesaria en las

26 Informe del oidor fiscal de la Audiencia de Manila, Manila, 24 de octubre de 1776, AGI, Filipinas, 652.

R. I., $1999, \mathrm{n}^{\circ} 215$ 
islas: la creación de una casa para recluir a las mujeres de mala vida y a las condenadas por la sala del crimen.

De la misma opinión era el oidor don Juan Bautista Bonilla y Jimeno: una vez fallecida la fundadora, su obra debía desaparecer también. A su juicio no había nadie capacitado para continuarla, y su prosecución supondría un gravamen insostenible para la ciudad de Manila.

Ciertamente, el informe pedido a la madre Paula sobre el origen de los ingresos con que mantenía su casa de recogimiento y enseñanza había dejado claro que no eran los habitantes de Manila quienes la sostenían, sino la generosidad de algunos bienhechores de Nueva España, y que hacía seis años que la citada madre Paula no pedía limosnas en las islas. Pero, para Bonilla, el fallecimiento de ésta conllevaría el cese de las limosnas recogidas de sus «apasionados». Entonces el mantenimiento del beaterio recaería sobre los habitantes de la capital, «quienes se hallan gravadísimos» ${ }^{27}$.

\section{LA RESOLUCIÓN REAL}

El expediente completo, con los informes divergentes de los oidores de la Audiencia de Manila, fue visto en el Consejo el 26 de marzo de 1779. Cinco meses más tarde, el fiscal firmó su informe en el que se limitaba a una reconsideración de los argumentos de los oidores. En realidad, puesto que todos ellos se habían mostrado partidarios del mantenimiento de la casa de recogimiento al menos durante la vida de su fundadora, el fiscal adoptó la misma postura, sin aventurarse a ir más allá. Efectivamente, consideró que el beaterio podía mantenerse en el estado en que se encontraba hasta el fallecimiento de la madre Paula, ya que no era gravoso a la sociedad de Manila. Eso sí, prohibiendo que aumentara el número de educandas.

En el momento en que se produjera la muerte de la fundadora, el beaterio desaparecería al unirse, como proponía el oidor Uruñuela, al

27 Los informes de los oidores de la Audiencia se encuentran también en AGI, Filipinas, 652. Están fechados en Manila, a 21 de mayo de 1778 e incluidos en los autos con que se dio cuenta al rey, fols.81v-85. Estos autos se acompañaron de una carta de la Audiencia de Manila, fechada en la capital a 6 de julio de 1778. Este documento se encuentra también en AGI, Filipinas, 652. El informe de la madre Paula citado fue evacuado en cumplimiento de un auto de la Audiencia fechado en Manila, a 9 de julio de 1777. 
de la Compañía o al de Santa Catalina, que había de regirse entonces por unas reglas nuevas. También manifestó la conveniencia de que se levantara una casa galera en la que se recogieran las mujeres libertinas o delincuentes, ya que su contacto con las jóvenes educandas podía ser perjudicial para éstas ${ }^{28}$.

El Consejo fue del mismo sentir que el fiscal, aunque propuso la agregación de la casa de la madre Paula, tras su fallecimiento, a los colegios de Santa Catalina y de Santa Isabel, y obvió el tema de la casa de reclusión para mujeres. Este fue el contenido de la real cédula, firmada en San Ildefonso a 22 de septiembre de 1779, con que se dio cuenta de la resolución real en esta materia al gobernador y a la $\mathrm{Au}$ diencia de las islas, quedando así el asunto definitivamente zanjado.

Recibida la resolución real en las islas, fue acatada en todo su tenor, procediéndose al recuento de las niñas recogidas a fin de garantizar que no se agregasen otras, tal y como lo prohibía la real cédula. Sin embargo, los problemas con el beaterio volvieron a plantearse al fallecer, en el término de un año, la fundadora, y ser necesario proceder a la disolución de la casa de recogimiento.

\section{EL FUTURO DEL BEATERIO}

En este momento, la Audiencia pidió al provincial de dominicos y al proveedor de la Casa de la Misericordia (de quienes dependían los colegios de Santa Isabel y Santa Catalina) informes sobre el número de jóvenes que podían recibir. Las respuestas de ambos fueron coincidentes: ninguno de los dos centros estaba en condiciones de incrementar el número de sus colegialas, ya que les era muy difícil incluso reunir los recursos precisos para subvenir a las necesidades que ya tenían.

Con respecto al beaterio de Santa Catalina, el provincial de los dominicos asegura que se hallaba en una situación de suma pobreza, sosteniéndose desde hacía treinta años con los auxilios de la provincia del Santísimo Rosario, ya que no se percibían las rentas de que debía mantenerse. De ahí que se limitara el número de educandas y maestras, y que la orden de predicadores estuviera deliberando acer-

28 Casa galera: prisión para mujeres criminales. Vista del Fiscal del Consejo, Madrid, 20 de agosto de 1779. AGI, Filipinas, 652.

R. I., $1999, \mathrm{n}^{\circ} 215$ 
ca del futuro del beaterio, «por no poder ya soportar los gastos que se van recreciendo con la carestía de los víveres que experimenta esta república en toda la extensión de sus géneros» ${ }^{29}$.

Esta situación forzaba a pedir que se excusara al beaterio del cumplimiento de la orden relativa a acoger a las jóvenes de la casa fundada por la madre Paula, o que se libraran cantidades suficientes para hacer frente a su mantenimiento.

En cuanto al colegio de Santa Isabel, el proveedor y los diputados de la Hermandad de la Santa Misericordia, aseguran que su situación era bastante apurada: el número de niñas del colegio estaba directamente condicionado por los escasos ingresos de que disponía, y era imposible hacerse cargo de un número mayor, si no se señalaban nuevas rentas.

No eran estos los únicos factores que la Audiencia tenía que tomar en consideración; existía también el testamento de la madre Paula, con precisas instrucciones sobre la casa de recogimiento y escuela por ella fundada. En este documento deja en su lugar, como encargada de la educación y de cumplir las contratas con los padres de las niñas, a Ignacia de Guzmán de la Santísima Trinidad, quien había asumido esta responsabilidad tiempo atrás por la enfermedad de la fundadora. A ella le encomienda encarecidamente que realice las gestiones precisas ante la Audiencia de las islas y el arzobispo, a fin de que persista la casa «en el mismo modo que hasta aquí se ha gobernado». Su mantenimiento estaba asegurado por las limosnas que recibía de sus bienhechores, y por lo ingresado por los trabajos que realizaban las niñas, nombradas herederas de todos sus bienes por la madre Paula ${ }^{30}$.

Este encargo fue cumplido escrupulosamente por la hermana Ignacia quien solicitó a la Audiencia la continuación de la casa, según lo estipulado en el testamento de la fundadora. Para ello, insistió en

29 El provincial de Santo Domingo, fray Cristóbal Rodríguez, a la Audiencia, convento de Santo Domingo de Manila, 6 de septiembre de 1782, AGI, Filipinas, 652.

30 Testimonio del testamento de la madre Paula de la Santísima Trinidad, otorgado ante escribano en Manila, a 2 de junio de 1782. En este documento también se cita a Cristina Juana de la Santísima Trinidad, Petrona Jabala y Rafaela Dueñas de la Santísima Trinidad, en quienes deposita su confianza, para la continuación de la casa, por «haberlas criado desde pequeñas y haberle cuidado a la educación y enseñanza de las niñas, y tener satisfacción de que gobernarán la casa en el lugar y grado que van referidas». AGI, Filipinas, 652. 
que la obra podía mantenerse con las limosnas de los bienhechores, las cuales continuarían pese al fallecimiento de la madre Paula.

«Esta casa, señor, aunque ha faltado la maestra María Paula, tiene el mismo beneficio para la subsitencia y manutención de las niñas educandas, pues, a más de las costuras que ayudan a ella, don Manuel Quevedo, que en la Nueva España colecta las limosnas que anualmente remite, continuará las remesas, como él mismo ha escrito, y cuando él falte, los bienhechores tienen dispuesto quién haga dicha colección, para que no cese dicha limosna» 31 .

También quedaba asegurada la enseñanza de las niñas, confiada a antiguas alumnas de la hermana Paula que seguían el mismo método que ésta había empleado para su formación. Sus nombres quedaban recogidos en el testamento citado, y no se debía tomar en cuenta su condición de indias, ya que también lo eran las maestras de los beaterios de Pasig, de San Sebastián y de la Compañía, y desarrollaban su labor eficazmente ${ }^{32}$.

De esta forma, garantizado el sustento material de las educandas, y también su formación, sólo se oponía a la continuación de la casa de enseñanza y recogimiento la real cédula de 22 de septiembre de 1779. Esta había sido firmada para amparar a las niñas, de modo que, si la Audiencia exponía al rey las condiciones en que se encontraba la casa tras la muerte de la fundadora, se podría cambiar la voluntad real. No había que olvidar tampoco que la casa cumplía una función muy importante y que cubría necesidades que no quedaban satisfechas con los colegios existentes en la ciudad.

«En esta casa, señor, se reciben de todas calidades: españolitas, inditas, negritas, mestizas y montaraces. Aquí se logra el fin de enseñarles

31 Petición de Ignacia de Guzmán de la Santísima Trinidad a la Audiencia, s.f. AGI, Filipinas, 652.

32 Otro caso aducido como ejemplo es el monasterio de Corpus Christi de México, fundado por monjas indias. La propia Ignacia de Guzmán era china, natural del pueblo de Balanga, en la provincia de Batán. Las otras maestras designadas por la hermana Paula eran Petronia Jabala, de «cincuenta y tantos años», india, natural de Macabebe, en la provincia de la Pampanga; Rafaela Dueñas, de 55 años, y natural también de Macabebe (aunque no se indica nada, es fácil deducir que sería también india); y Cristina Juana, china de 38 años y natural de Tambobo, en la provincia de Tondo. El testamento de la madre Paula hace referencia a una quinta maestra, cuyo nombre, sin embargo, no aparece en el traslado del citado documento que he consultado.

R. I., $1999, \mathrm{n}^{\circ} 215$ 
la doctrina cristiana, que la entiendan y que la guarden, que es el fin principal de esta casa, que sepan asimismo las cosas usuales correspondientes al sexo, para que cuando tomen estado sepan y puedan cumplir con las obligaciones de él. Es mucho el fruto que se ha experimentado en niñas, no sólo cimarronas o montaraces, sino aun de estas inmediaciones que han venido a esta casa a buscar el camino seguro de salvarse, que es la ley santa de Dios y la doctrina cristiana ${ }^{33}$.

Ante esta situación, la Audiencia optó por mantener el beaterio de la madre Paula, bajo la administración de la maestra señalada en su testamento por la fundadora, para sucederla tras su fallecimiento. Ignacia de Guzmán de la Santísima Trinidad quedó, pues, al frente del beaterio con la prohibición expresa de no recibir más niñas de las que en ese momento tuviera, y con la obligación de no innovar cosa alguna en cuanto a la dirección de la casa, manteniéndose todo en la forma en que lo había dejado la madre Paula, en tanto el rey, informado de todo, resolviera otra cosa. La Audiencia, por su parte, vigilaría el exacto cumplimiento de todo lo acordado ${ }^{34}$.

El informe que la Audiencia de Manila remitió a la corte incluyó también unas consideraciones sobre el beaterio y casa de enseñanza, y la labor que desde su fundación había venido desarrollando. Así, aseguró que consideraba útil su persistencia, y que de él habían salido ya monjas para el monasterio de Santa Clara, otras habían ingresado en el beaterio de Santa Catalina o se habían casado. Muerta la fundadora, cabía esperar los mismos frutos bajo la dirección de la hermana Ignacia de Guzmán, «por el recogimiento, aplicación y virtud» con que continuaba la labor de la madre Paula. Por todo ello, era muy recomendable la conservación del beaterio.

«Se experimenta que viven racional y políticamente, y saben cumplir con las obligaciones de su estado, y las que, cumplido el término

33 Ibidem. Como se desprende del texto transcrito, la enseñanza de la mujer indígena parece limitarse al conocimiento de la doctrina cristiana y de las habilidades domésticas. Nada se dice en los documentos acerca de la enseñanza de la lectura y escritura. De hecho, la propia madre Paula no sabía firmar. Sobre el alcance de la educación proporcionada a la mujer indígena en la capital del virreinato en el siglo XVIII, véase E. LUQUE ALCAIDE, [1] pp. 279 y 282.

34 La notificación a la hermana Ignacia de Guzmán de lo resuelto por el real acuerdo ordinario de la Audiencia, con fecha de 16 de enero de 1783, tuvo lugar el día 27 del mismo mes.

R. I., 1999, n. ${ }^{\circ} 215$ 


\begin{abstract}
señalado de enseñanza, regresan a las provincias de donde vinieron, son muy atendidas en ellas y sirven de ejemplo y de maestras a las demás. Finalmente se advierte que esta casa es de mucha edificación en esta ciudad y se ve en ella respirar la vida cristiana, aun en las cimarronas o montaraces que vienen a ella para aprender la verdadera religión, sobre lo que ha habido varios ejemplares y casos de grande edificación» ${ }^{35}$.
\end{abstract}

\title{
LA VIDA INTERNA DEL BEATERIO
}

Las dos relaciones de las mujeres y niñas recogidas en el beaterio, que se hicieron por mandato de la Audiencia de las islas, nos proporcionan alguna información sobre la realidad del centro. Entre ambas median siete años, pero no hay variación en el número de ellas; en ambos casos son setenta los nombres que figuran en las listas, excepción hecha de las tres niñas que pagan sus alimentos y de las dos mujeres que habían sido recogidas por los tribunales y que también se incorporan en la relación del año 1781.

En cuanto a las provincias de procedencia, la mayor parte de ellas proceden de Tondo (34 en la lista de 1774, y 23 en la de 1781), siguiéndole a continuación las naturales de la Pampanga (13 en 1774, y 17 en 1781), aunque por lo general la procedencia es muy variada, como se puede apreciar en las tablas incluidas en el apéndice. En cuanto a su raza, sólo en la lista del año 1781 se detalla este particular: la mayor parte de ellas son indias, seguidas de las chinas y las mestizas (de chino, y de español). Un dato curioso es la presencia de tres jóvenes, de 19, 13 y 11 años, llamadas «morenas libertad». Las dos primeras proceden de la provincia de Tondo, y la última, de Batavia (Java).

Por lo que respecta a los años, es frecuente que se desconozca su edad, determinándola entonces por el aspecto físico. Pero en los casos en que este particular se conoce, las edades son muy variadas, siendo las más jóvenes niñas de cuatro años.

Mientras todos los trámites ya expuestos se realizaban, la vida del beaterio se desarrollaba dentro de los cauces normales. Testimonio de ello son las referencias incluidas en los documentos relativas a la formación de las educandas y a su marcha del beaterio, una vez concluí-

35 La Audiencia de Manila, al rey, Manila, 23 de junio de 1783, AGI, Filipinas, 652. El fallecimiento de la madre Paula tuvo lugar el 16 de junio de 1782 . En este momento había 74 indias en el beaterio.

R. I., $1999, \mathrm{n}^{\circ} 215$ 
da ésta. Es ilustrativa en este sentido, la salida del beaterio para tomar el hábito de una joven que ingresó en el convento de Santa Clara. La ceremonia es recreada por los documentos y a través de ellos podemos vivir el desarrollo del acontecimiento en su ritmo lento y solemne.

La noticia del ingreso de la joven en el convento fue comunidada por la rectora del beaterio, Ignacia de Guzmán, al gobernador, a fin de que éste enviara al escribano de cámara para que diera fe del acto «porque esto es parte del fruto que dicha casa da y conviene al derecho de ella que su majestad (...) tenga esta noticia». Su petición fue satisfecha y del desarrollo de los actos quedó testimonio, que sería más tarde remitido a la corte.

La ceremonia se desarrolló con gran solemnidad el 28 de septiembre de 1782, conforme a un plan minuciosamente preparado. Así, los actos comenzaron a las cuatro de la tarde en el beaterio que se encontraba engalanado. Allí fueron concurriendo «varias señoras de esta república y, entre ellas, algunas de la primera distinción» quienes acompañaron a la joven que estaba ricamente vestida «con palma y corona», hasta el oratorio donde se había instalado un altar portátil, «compuesto y con muchas luces». Dos maestras, las hermanas Ignacia y Cristina de la Santísima Trinidad, la acompañaron hasta los pies de la imagen de la Virgen que presidía el altar, donde rezó y después se despidió de sus maestras y compañeras.

Entonces se formó la comitiva que se encaminó a la iglesia del monasterio de santa Clara, donde fue recibida por los religiosos de san Francisco. Ante el altar mayor de nuevo se recogió la joven en oración para pasar después al monasterio, ante cuya entrada había gran concurso de vecinos. Recibida por las religiosas, con velos sobre los rostros y velas encendidas, la abadesa le hizo varias preguntas relativas a su vocación. A continuación la introdujeron en el convento entre cánticos, «y en este intermedio se sirvió un exquisito refresco, continuando la música». Media hora más tarde, la puerta del convento se volvió a abrir y apareció toda la comunidad acompañando a la profesa vestida ya de religiosa, manteniéndose entonces un rato de conversación con las señoras que habían asistido al acto, «hasta ya cerca de las oraciones», momento en que se recogieron todos ${ }^{36}$.

36 Testimonio del escribano de cámara, don Ramón de Orendain, sobre el ingreso de doña Luisa de San Buenaventura Arriola en el convento de santa Clara. Manila, 29 de septiembre de 1782. AGI, Filipinas, 652. 


\section{LA PERSEVERANCIA PREMIADA: LA CONSERVACIÓN Y FOMENTO DEL BEATERIO}

El informe sobre todo lo obrado por la Audiencia en el tema del beaterio fue redactado el 23 de julio de 1783 y enviado a la corte. El fiscal del Consejo se manifestó favorable a la aprobación de todo lo actuado por la Audiencia de las islas, entendiendo que había tenido fundadas razones para suspender el cumplimiento de lo dispuesto por la real cédula de 22 de septiembre de 1779 , relativo al cierre del beaterio y al traslado de las niñas a colegios de la ciudad de Manila. De esta forma, aprobó la continuación de dicha casa de recogimiento y enseñanza bajo la dirección de la hermana Ignacia de Guzmán (con la cláusula de «por ahora»), pero siempre sometida a la supervisión de la Audiencia que debía informar sobre cualquier novedad que aconteciera.

El Consejo de Indias fue del mismo sentir que el fiscal, aunque resolvió suprimir la cláusula de «por ahora» y dar a la aprobación del beaterio un carácter definitivo. Así, encargó a la Audiencia que adoptara las medidas conducentes para la subsistencia y promoción de la casa de enseñanza, y para el aumento del número de educandas. De todo ello y de sus progresos debía dar cuenta al Consejo.

Este resolvió también la expedición de cédulas al gobernador, al arzobispo, a la ciudad y al Consulado de Manila a fin de que, informados de todo, contribuyeran con su esfuerzo y generosidad a la conservación y florecimiento de la citada casa de enseñanza ${ }^{37}$.

La real cédula, firmada en San Ildefonso a 13 de agosto de 1784 sancionaba lo acordado por la Audiencia y hacía ver el empeño que el soberano tenía en el progreso de la expresada obra. En este punto, conviene hacer notar una cuestión, y es la distinción que parece establecerse en la fundación de la madre Paula, entre el recogimiento y la casa de enseñanza. En un principio ambas funciones se habían desarrollado juntas, pero ahora tanto el fiscal, como el Consejo o el propio rey se refieren exclusivamente a la vertiente educativa de la

Aunque los datos proporcionados por los documentos no son muy precisos, podemos deducir que la joven profesa era mestiza española, natural de Manila y que contaba con 19 años. Véase la «Relación de mujeres y educandas recogidas en el beaterio» realizada el 14 de agosto de 1781, e incorporada al apéndice.

37 Vista del fiscal del Consejo, Madrid, 26 de junio de 1784 y resolución del Consejo de Indias, 30 de junio de 1784. Ambos en AGI, Filipinas, 652.

R. I., $1999, \mathrm{n}^{\circ} 215$ 
fundación. Probablemente este hecho se deba a las disposiciones reales sobre enseñanza de la población indígena, y a la necesidad que de este centro se sentía en Manila. En este segundo punto es preciso recordar que si en un principio se estimó que la fundación no cubría ningún vacío, sino que podría perjudicar el progreso de otros centros de enseñanza, en 1783 la situación se había invertido. Los centros de enseñanza existentes en la capital atravesaban importantes apuros económicos, mientras que la citada casa mantenía un considerable número de pupilas con unas finanzas saneadas. Por otro lado, no hay que olvidar que se dedicaba fundamentalmente a la formación de las indias y castas, más desatendidas en este aspecto que la población española ${ }^{38}$.

La real cédula fue aprovechada por la hermana Ignacia de Guzmán para solicitar ayudas para el sostenimiento de la casa de enseñanza y para la manutención de las educandas. Así, lo hizo ante el Tribunal del Consulado de Manila, que en su junta general del 21 de mayo de 1787 acordó por unanimidad conceder una ayuda de doscientos pesos anuales sobre la caja de fondos del derecho de avería. Esta medida fue aprobada por decreto del gobernador de 25 de mayo de 1787, en tanto se informara al rey y éste decidiera lo más conveniente ${ }^{39}$.

A primera vista, puede resultar sorprendente la disposición del Consulado de colaborar con el sostenimiento de una obra que años atrás se había considerado innecesaria y gravosa para la sociedad manilense. Sin embargo, las circunstancias habían cambiado y la ciudad conocía un renacer del comercio que alcanzaría su momento más importante en los años 1789 a 1800 con la apertura total del puerto. Este florecimiento de la actividad mercantil redundaría en una evidente mejora de la situación económica y favorecería una mayor generosidad por parte de la sociedad pudiente de Manila ${ }^{40}$.

Dos años más tarde, el asunto volvió a ser tratado en el Consejo, previo informe favorable del contador general. Así, el fiscal en su

38 Los traslados de las reales cédulas remitidas al arzobispo, gobernador, Audiencia, consulado y ciudad de Manila se encuentran todos en AGI, Filipinas, 652.

$39 \mathrm{El}$ apoderado del real consulado y comercio de Manila, don Miguel de Orbaneja y Ortega, al rey, Madrid, 25 de septiembre de 1788. AGI, Filipinas, 652. El asunto fue sometido al informe del ministro asesor del gobierno, el oidor don Manuel del Castillo y Negrete, y con fecha de 25 de mayo de 1787 el gobernador firmó el decreto por el que se daba el visto bueno al acuerdo del Real Tribunal del Consulado.

40 Véase M.L. Diaz-Trechuelo, [23] 
dictamen manifestó su aprobación de todo lo obrado por el Consulado y expresó su parecer, favorable a la expedición de la real cédula que aquél solicitaba. Asimismo, era de la opinión de que se debía expresar el agradecimiento real por la asignación fijada y animar a que «continuara en la protección de este recogimiento por cuantos medios se le proporcionen ${ }^{41}$.

La real cédula firmada en San Lorenzo, a 17 de octubre de 1789 satisfizo la petición del Consulado de Manila, cuya generosidad fue agradecida, al tiempo que reiteraba el empeño real en que la fundación de la madre Paula continuara en pie $^{42}$.

\section{RELACION DE LAS EDUCANDAS Y COMPAÑERAS RECOGIDAS EN EL BEATERIO DE LA HERMANA PAULA DE LA SANTISIMA TRINIDAD.}

FECHA: 1-septiembre-1774

$\begin{array}{llll}\text { NOMBRE } & \begin{array}{l}\text { PUEBLO, O CIU- } \\ \text { DAD DE PROCE- }\end{array} & \text { PROVINCIA } & \text { EDAD } \\ & \text { DENCIA } & & \\ \text { Ignacia de Guzmán } & \text { Balanga } & \text { Batán } & 44 \\ \text { Rafaela Dueñas } & \text { Macabebe } & \text { Pampanga } & 47 \\ \text { María Vagas } & \text { Macabebe } & \text { Pampanga } & 44 \\ \text { Nicolasa de la Soledad } & \text { Puerto de Cavite } & \text { Cavite } & 41 \\ \text { Cristina Juana } & \text { Tambobo } & \text { Tondo } & 31 \\ \text { Catalina Ramírez } & \text { Balanga } & \text { Batán } & 42 \\ \text { Petrona Sabala } & \text { Macabebe } & \text { Pampanga } & 40 \\ \text { Micaela de Jesús } & \text { Apalit } & \text { Pampanga } & 30 \\ \text { Juana Punzalan } & \text { Apalit } & \text { Pampanga } & 25 \\ \text { María Rita } & \text { Apalit } & \text { Pampanga } & 23 \\ \text { Tomasa Arceo } & \text { Apalit } & \text { Pampanga } & 37 \text { poco más o } \\ \text { María Caingan } & \text { Apalit } & \text { Pampanga } & 28 \\ \text { Martina Pangilinan } & \text { Apalit } & \text { Pampanga } & 23 \\ \text { Nicolasa Magat } & \text { Macabebe } & \text { Pampanga } & 28 \\ \text { Josefa de la Rosa } & \text { Pililla } & \text { La Laguna } & 30 \\ \text { Ma Luisa Tomasina } & \text { Bulacán } & \text { Bulacán } & 33 \\ \text { Ma Florentina Noqui } & \text { Macabebe } & \text { Pampanga } & 22\end{array}$

41 Informe del fiscal del Consejo de Indias, Madrid, 19 de agosto de 1789. El informe de la contaduría general está fechado el 30 de julio.

42 El texto de la real cédula se encuentra en AGI, Filipinas, 652.

R. I., 1999, n. ${ }^{\circ} 215$ 


\begin{tabular}{|c|c|c|c|}
\hline $\begin{array}{l}\text { Matea de la Santísima } \\
\text { Trinidad }\end{array}$ & Los Batanas & Cagayán & 18 aprox. $(*)$ \\
\hline Juana Ponce & Apalit & Pampanga & 25 \\
\hline $\begin{array}{l}\text { Margarita Francisca } \\
\text { Camacho }\end{array}$ & Manila & Tondo & 44 \\
\hline $\begin{array}{l}\text { Vicenta Antonia de } \\
\text { Legazpi }(* *)\end{array}$ & Binondo & Tondo & 26 \\
\hline Bacelisia Herrera & Puerto de Cavite & Cavite & 20 \\
\hline María Francisca & Parañaque & Tondo & 30 \\
\hline $\mathrm{M}^{\mathrm{a}}$ Teresa Paredes & Capiz & Panay & 28 \\
\hline Lucía Rosa & $\begin{array}{l}\text { Santo Nombre de } \\
\text { Dios de Macao }\end{array}$ & China & 25 \\
\hline Dominga Pereyra & $\begin{array}{l}\text { Santo Nombre de } \\
\text { Dios de Macao }\end{array}$ & China & 16 aprox. \\
\hline $\begin{array}{l}\text { Rosa de la Santísima } \\
\text { Trinidad }\end{array}$ & $\begin{array}{l}\text { Santo Nombre de } \\
\text { Dios de Macao }\end{array}$ & China & 20 aprox. \\
\hline María Antonia & $\begin{array}{l}\text { Santo Nombre de } \\
\text { Dios de Macao }\end{array}$ & China & 16 aprox. \\
\hline $\mathbf{M}^{\mathrm{a}}$ Mauricia Candelaria & Cavite el Viejo & Cavite & $\begin{array}{l}\text { de } 15 \text { a } 16 \\
\text { años aprox. }\end{array}$ \\
\hline María Fabiana Cabrera & Manila & Tondo & $16+2$ \\
\hline Rufina Baltasara & Yndán & Cavite & 12 \\
\hline $\begin{array}{l}\mathbf{M}^{\text {a }} \text { Valeriana Chico de } \\
\text { Aguilar }\end{array}$ & Manila & Tondo & 14 \\
\hline $\begin{array}{l}\text { M }^{\mathrm{a}} \text { Manuela Ignacia de } \\
\text { la Santísima Trinidad }\end{array}$ & Malabón & Cavite & 18 aprox. \\
\hline 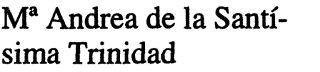 & Santa Cruz & Tondo & 18 aprox. \\
\hline $\mathbf{M}^{\mathrm{a}}$ Gerbancia Punzalan & Tondo & Tondo & 21 \\
\hline $\mathbf{M}^{\mathrm{a}}$ Tecla Punzalan & Tondo & Tondo & 18 aprox. \\
\hline Vicenta de la Soledad & Puerto de Cavite & Cavite & 12 \\
\hline Paula de la Soledad & Manila & Tondo & 12 \\
\hline $\begin{array}{l}\mathrm{M}^{\mathrm{a}} \text { Francisca de la Tri- } \\
\text { nidad }\end{array}$ & Santa Cruz & Tondo & 20 aprox. \\
\hline María Elena & Apalit & Pampanga & 15 \\
\hline $\mathrm{M}^{\mathrm{a}}$ Juana de la Cruz & Manila & Tondo & 12 \\
\hline $\mathrm{M}^{\mathrm{a}}$ de los Angeles & No sabe & No sabe & 25 \\
\hline $\begin{array}{l}\text { Angela de la Santísima } \\
\text { Trinidad }\end{array}$ & De los igorrotes & Pangasinán & 20 aprox. \\
\hline María Toribia & Binondo & Tondo & 14 aprox. \\
\hline $\mathbf{M}^{\mathbf{a}}$ Rita & Bulacán & Bulacán & 11 \\
\hline María Olalla Morena & Binondo & Tondo & 15 aprox. \\
\hline Catalina de los Santos & Binondo & Tondo & 14 aprox. \\
\hline María de la Cruz & Santa Cruz & Tondo & 18 \\
\hline 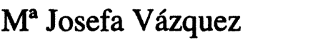 & Manila & Tondo & 15 \\
\hline $\mathbf{M}^{\mathrm{a}}$ Bernarda Sebastiana & Santa Cruz & Tondo & 19 \\
\hline $\mathbf{M}^{\mathrm{a}}$ Manuela de Jesús & Tondo & Tondo & 15 \\
\hline $\mathbf{M}^{\mathrm{a}}$ Martina Henríquez & Manila & Tondo & 15 \\
\hline $\begin{array}{l}\text { Ma Francisca de la }^{\mathrm{a}} \\
\text { Santísima Trinidad }\end{array}$ & Manila & Tondo & 15 \\
\hline María Ramírez & Balanga & Batán & 14 \\
\hline
\end{tabular}




\begin{tabular}{|c|c|c|c|}
\hline $\begin{array}{l}\text { Ana de la Santísima } \\
\text { Trinidad }\end{array}$ & Manila & Tondo & 15 \\
\hline Dominga de Jesús & Tambobón & Tondo & 13 \\
\hline $\mathrm{M}^{\mathrm{a}}$ Candelaria de Jesús & Tondo & Tondo & 11 \\
\hline$M^{\mathrm{a}}$ Francisca Vicenta & Binondo & Tondo & 7 \\
\hline $\begin{array}{l}\text { Ma Clara de la Santísi- } \\
\text { ma Trinidad }\end{array}$ & Binondo & Tondo & 7 \\
\hline $\begin{array}{l}\mathbf{M}^{a} \text { Andrea de los San- } \\
\text { tos }\end{array}$ & Binondo & Tondo & 4 y medio \\
\hline María Agueda & Binondo & Tondo & 7 \\
\hline$M^{a}$ Micaela & Binondo & Tondo & 10 \\
\hline Florentina de Lara & Orani & Batán & 11 \\
\hline $\mathrm{M}^{\mathrm{a}}$ Manuela & $\begin{array}{l}\text { Santiago Extramu- } \\
\text { ros de Manila }\end{array}$ & Tondo & 7 \\
\hline $\begin{array}{l}\text { Ma Punciana de la San- }^{\text {ásima Trinidad }}\end{array}$ & Bulusán & Visayas & 38 \\
\hline Ma Bárbara & Manila & Tondo & 20 aprox. \\
\hline $\begin{array}{l}\text { Ma Paula de la Santísi- } \\
\text { ma Trinidad }\end{array}$ & Tondo & Tondo & 3 y medio \\
\hline $\begin{array}{l}M^{a} \text { Feliciana de la San- } \\
\text { tísima Trinidad }\end{array}$ & Manila & Tondo & 4 \\
\hline $\begin{array}{l}\mathrm{M}^{\mathrm{a}} \text { Manuela de la San- } \\
\text { tísima Trinidad }\end{array}$ & Manila & Tondo & 9 \\
\hline
\end{tabular}

(*) Cuando la edad aparece acompañada de la abreviatura «aprox», indica que la interesada desconoce su edad, y ésta se establece en función de su aspecto físico. En el caso señalado con el asterisco, en la relación se indica que «no supo dar razón de su edad por ser recién convertida y bautizada, pero por el aspecto pareció de dieciocho años».

(**) El documento indica que es mestiza.

(***) Los datos de esta tabla han sido extraídos de la relación de las setenta «educandas y compañeras» recogidas en el beaterio, realizada por el escribano de Cámara, don Ramón de Orendaín (a partir de los datos proporcionados por la hermana Paula de la Santísima Trinidad), en cumplimiento de lo ordenado por el Real Acuerdo de 29 de agosto de 1774. La relación está fechada en Manila, a 1 de septiembre de 1774. AGI, Filipinas, 652.

RELACION DE MUJERES Y EDUCANDAS RECOGIDAS EN EL BEATERIO DE LA HERMANA PAULA DE LA SANTISIMA TRINIDAD (14-agosto-1781)

\begin{tabular}{|c|c|c|c|}
\hline NOMBRE & PROCEDENCIA & PROVINCIA & $\begin{array}{l}\text { EDAD, NACION Y } \\
\text { OTROS DATOS }\end{array}$ \\
\hline Ignacia de Guzmán & Balanga & Batán & 51, doncella. Sangley \\
\hline Petrona Javala & Macabebe & Pampanga & $\begin{array}{l}50 \text { y tantos, doncella. } \\
\text { India }\end{array}$ \\
\hline $\begin{array}{l}\text { Mariana Romana } \\
\text { Florentina Nunque }\end{array}$ & $\begin{array}{l}\text { Macabebe } \\
\text { Macabebe }\end{array}$ & $\begin{array}{l}\text { Pampanga } \\
\text { Pampanga }\end{array}$ & $\begin{array}{l}50 \text { doncella. India } \\
24 \text { doncella }\end{array}$ \\
\hline
\end{tabular}

R. I., $1999, \mathrm{n}^{\circ} 215$ 


\begin{tabular}{|c|c|c|c|}
\hline Rafaela Dueñas & Macabebe & Pampanga & 55 doncella \\
\hline Nicolasa Dueñas & Macabebe & Pampanga & 60 doncella. India \\
\hline Inés Caluran & Macabebe & Pampanga & 27 doncella. India \\
\hline $\begin{array}{l}\text { Tomasa de la Stma. } \\
\text { Trinidad }\end{array}$ & Macabebe & Pampanga & 10 \\
\hline Rafaela Dueñas & Macabebe & Pampanga & 10 India \\
\hline Martina Pangilinan & Apalit & Pampanga & 30 doncella. India \\
\hline Margarita Francisca & $\begin{array}{l}\text { Arroceros, extra- } \\
\text { mu- ros de Manila }\end{array}$ & Tondo & 51 doncella. Sangley \\
\hline Juana Punzalan & Apalit & Pampanga & 32 doncella. India \\
\hline Vicenta García & Apalit & Pampanga & 25 doncella. India \\
\hline$M^{a}$ Rita Vergara & Apalit & Pampanga & 30 doncella. India \\
\hline Elena Pangilinan & Apalit & Pampanga & 18 doncella. India \\
\hline Cristina Juana & Tambobo & Tondo & 38 doncella. Sangley \\
\hline $\begin{array}{l}\mathrm{M}^{\mathrm{a}} \text { Francisca de la } \\
\text { Stma. Trinidad }\end{array}$ & Parañaque & Tondo & 33 doncella. India \\
\hline Luisa Tomasina & & Bulacán & 37 viuda. India \\
\hline $\mathbf{M}^{\mathrm{a}}$ Irene Paredes & Capis & Visayas & $\begin{array}{l}36 \text { doncella. Mestiza } \\
\text { de español }\end{array}$ \\
\hline Rufina Baltasara & Yndan & Cavite & 20 doncella. Española \\
\hline Josefa Savina & Tanavan & Batangas & 38 viuda \\
\hline Lorenza Carrión & Minalín & Pampanga & 20 doncella. India \\
\hline Manuela Carrión & Minalín & Pampanga & 21 doncella. India \\
\hline Margarita de Guzmán & Balanga & Batán & 20 doncella. Sangley \\
\hline Juana de Guzmán & Balanga & Batán & 15 doncella. Sangley \\
\hline $\mathrm{M}^{\mathrm{a}}$ Flores & Balanga & Batán & 20 doncella. India \\
\hline Catalina Ramírez & Balanga & Batán & 48 doncella. India \\
\hline María Ramírez & Balanga & Batán & 20 doncella. India \\
\hline Juana Suba & Candava & Pampanga & 26 doncella. India \\
\hline Paula de la Soledad & Puerto de Cavite & Cavite & 20 doncella. India \\
\hline $\mathrm{M}^{\mathrm{a}}$ de la Cruz & Tondo & Tondo & 10. India \\
\hline $\begin{array}{l}\text { Leocadia de la Stma. } \\
\text { Trinidad }\end{array}$ & Tondo & Tondo & 6. India \\
\hline $\begin{array}{l}\text { Ma Paula de la Stma. } \\
\text { Trinidad }\end{array}$ & Tondo & Tondo & 12. Sangley \\
\hline $\mathrm{M}^{\mathrm{a}}$ de Jesús & Tondo & Tondo & $\begin{array}{l}17 \text { doncella. Mestiza } \\
\text { de Sangley }\end{array}$ \\
\hline $\mathbf{M}^{\mathrm{a}}$ Micaela & Tondo & Tondo & 17 doncella. Española \\
\hline Rosa de Jesús & Tambobo & Tondo & 10. India \\
\hline 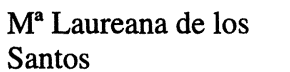 & & Naga & 20 doncella \\
\hline Dominga Pereyra & $\begin{array}{l}\text { Puerto de Macao. } \\
\text { China }\end{array}$ & & $\begin{array}{l}18 \text { doncella. China } \\
\text { «católica cristiana». }\end{array}$ \\
\hline Ana $\mathrm{M}^{\mathrm{a}}$ Quesada & $\begin{array}{l}\text { Puerto de Macao. } \\
\text { China }\end{array}$ & & $\begin{array}{l}\text { más de } 20 \text { doncella } \\
\text { China «católica cris- } \\
\text { tiana». }\end{array}$ \\
\hline Lucía Rosa & $\begin{array}{l}\text { Puerto de Macao. } \\
\text { China }\end{array}$ & & $\begin{array}{l}35 \text { doncella China } \\
\text { «católica cristiana». }\end{array}$ \\
\hline $\begin{array}{l}\text { Rosa de la Stma. Tri- } \\
\text { nidad }\end{array}$ & $\begin{array}{l}\text { Puerto de Macao. } \\
\text { China }\end{array}$ & & 28 doncella. China \\
\hline
\end{tabular}




\begin{tabular}{|c|c|c|c|}
\hline $\mathbf{M}^{\mathrm{a}}$ Antonia & $\begin{array}{l}\text { Puerto de Macao. } \\
\text { China }\end{array}$ & & 18 doncella. China \\
\hline $\begin{array}{l}\mathbf{M}^{\mathrm{a}} \text { Francisca de la } \\
\text { Stma. Trinidad }\end{array}$ & Santa Cruz & Tondo & 30 doncella. Sangley \\
\hline $\mathrm{M}^{\mathrm{a}}$ Juana & Binondo & Tondo & 19 doncella. Sangley \\
\hline $\mathbf{M}^{\mathrm{a}}$ Toribia & Binondo & Tondo & 13 «Morena libertad» \\
\hline $\begin{array}{l}\text { Ana M }{ }^{\mathrm{a}} \text { de la Con- } \\
\text { cepción }\end{array}$ & Santa Cruz & Tondo & 10. Sangley \\
\hline $\mathrm{M}^{\mathrm{a}}$ Agustina & $\begin{array}{l}\text { Estancia de Mala- } \\
\text { bón }\end{array}$ & Cavite & 23 doncella. India \\
\hline $\mathbf{M}^{\mathrm{a}}$ Silberia & Binondo & Tondo & 24 doncella. India \\
\hline $\mathbf{M}^{\mathrm{a}}$ Rita de Casia & Bulacán & Bulacán & 18 doncella. India \\
\hline $\mathrm{M}^{\mathrm{a}}$ Mauricia & Puerto de Cavite & Cavite & 20 doncella. India \\
\hline Felipa Aguierre & Puerto de Cavite & Cavite & 15 \\
\hline $\mathrm{M}^{\mathrm{a}}$ Andrea aguirre & Puerto de Cavite & Cavite & 14. Mestiza española \\
\hline $\mathrm{M}^{\mathrm{a}}$ Manuela & Bagumbayan & Tondo & 14 doncella. India \\
\hline $\mathrm{M}^{\mathrm{a}}$ Clara & Binondo & Tondo & 13. India \\
\hline Agueda Morales & Binondo & Tondo & $\begin{array}{l}14 \text { doncella. mestiza } \\
\text { española }\end{array}$ \\
\hline Luisa Isabel & Surigao & Visayas & 13 doncella. India \\
\hline $\begin{array}{l}\text { Juana de la Stma. } \\
\text { Trinidad }\end{array}$ & Manila & Tondo & 22 doncella. India \\
\hline Fabiana Cabrera & Manila & Tondo & 24 doncella. Española \\
\hline Vicenta Vázquez & Manila & Tondo & 16 doncella. Española \\
\hline Juana Ponce & Apalit & Pampanga & 30 doncella. India \\
\hline $\mathbf{M}^{\mathrm{a}}$ del Rosario & Malolos & Bulacán & 39 doncella. India \\
\hline $\mathrm{M}^{\mathrm{a}}$ Arriola & Manila & Tondo & $\begin{array}{l}19 \text { doncella. Mestiza } \\
\text { española }\end{array}$ \\
\hline $\begin{array}{l}\text { Angela de la Stma. } \\
\text { Trinidad }\end{array}$ & Bugabón & Pangasinán & 30 doncella. India \\
\hline $\begin{array}{l}\text { Matea de la Stma. } \\
\text { Trinidad }\end{array}$ & Batán & Cagayán & 25 doncella. India \\
\hline $\mathrm{M}^{\mathrm{a}}$ Feliciana & Manila & Tondo & 12. India \\
\hline $\mathrm{M}^{\mathrm{a}}$ de los Angeles & Malolos & Bulacán & 27 doncella. India \\
\hline $\mathrm{M}^{\mathrm{a}}$ Manuela & Manila & Tondo & $\begin{array}{l}19 \text { doncella. «morena } \\
\text { libertad» }\end{array}$ \\
\hline $\begin{array}{l}\text { Ma Josefa de la Con- } \\
\text { cepción }\end{array}$ & Vatavia & & 11 «morena libertad» \\
\hline $\mathbf{M}^{\mathrm{a}}$ Catalina de Siena & Manila & Tondo & 11 Española \\
\hline
\end{tabular}

\section{NIÑAS RECOGIDAS QUE PAGAN SUS ALIMENTOS \\ NOMBRE \\ $M^{\mathrm{a}}$ Inocencia Espinosa \\ $\mathbf{M}^{\mathrm{a}}$ Bárbara Vicenta \\ $\mathbf{M}^{\mathrm{a}}$ de Jesús \\ Manila \\ Binondo \\ Binondo \\ PROVINCIA \\ Tondo \\ Tondo \\ Tondo \\ EDAD Y NACION \\ 9 \\ 11. Española \\ 11. Mestiza de San- gley}

R. I., $1999, \mathrm{n}^{\circ} 215$ 


$\begin{array}{lccl}\text { MUJERES DEPOSITADAS POR LOS TRIBUNALES } & \\ \text { NOMBRE } & \text { PROCEDENCIA } & \begin{array}{l}\text { EDAD Y } \\ \text { ESTADO }\end{array} & \text { OTROS DATOS } \\ \text { Bernarda Agustina } & \text { Santa Cruz } & 28, \text { casada } & \begin{array}{l}\text { Mestiza de Sangley. } \\ \text { Depositada por provi- } \\ \text { dencia de la Audiencia }\end{array} \\ \text { M. }{ }^{\text {a Ciriaca }} & \text { Puerto de Cavite } & 20, \text { soltera } & \begin{array}{l}\text { India, depositada por } \\ \text { el Juez Provisor del } \\ \text { Arzobispado. }\end{array}\end{array}$

\section{LIMOSNAS RECIBIDAS EN ESPECIE EN EL BEATERIO DE LA COMPAÑÍA} (AÑOS 1769-1773)43.

-8 gantas de cacao

-2 cates de canela

-10 tinajas de aceite

-7 cavanes de mongos

$-1 / 2$ cavan de frijoles

- 9 piernas de carne

-9 pilones de azúcar

- 1 cavan de culantro

-8 cavanes y $1 / 2$ de sal

$-174 \operatorname{cocos}$

$-1 / 2$ pico de cebollas

-7 cestos de brea

- 5 docenas de platillos de loza

-20 docenas de platos de mayor a menor finos y bastos

-4 docenas de tazas calderas

- 3 docenas para chocolate

-3 docenas de platones

- 528 cavanes de arroz cáscara

- 10 cavanes de arroz limpio

43 Datos extraídos de la «Razón individual de las limosnas, así en plata como en especie, y de lo que producen las lavadas, costuras y cigarros que se doblan y se venden en este beaterio, computando un año con otro, por un quinquenio», AGI, Filipinas, 652. 


\section{LIMOSNAS RECIBIDAS EN ESPECIE EN EL HOSPITAL DE SAN JUAN DE DIOS (AÑOS 1772-1774)}

-62 pesos, 6 reales y 6 granos de pan

- 478 cavanes de palay, o arroz cáscara

- Una tinaja de aceite

-2 cavanes de tamarindo

-5 tinajas de miel

-4 tinajas de broas y marquezoles

- Unos cajones de bizcocho

- 10 piezas de lienzo azul

-2 pilones de azúcar

-25 pesos, 6 reales y 6 granos de carne y tasajo

- Una vaquita

-2 toretes

- Unos manteles, servilletas y camisas

-3 pesos, 7 reales y 6 granos de manteca

- 15 cestos de arroz pinava

- 16 gantas de arroz limpio

-6 botellas de vino de misas

- Una ganta de cacao

- Un toro capón

- Una ternera

- 30 piezas de medriñaque

- 3 cajones grandes de tasajo de vaca

- 7 tinajas de puerco en salmuera, «las dos gastadas más de la mitad»

- Una tinaja de pajo

- Media tinaja de tomates en salmuera para guisar

- Una tinaja de rosquetes «ya podridos e inservibles»

- Una tinaja y media de manteca

- Una tinaja de chocolate

- Un lío de tasajo

-7 tinajas de sal

-2 cajones de bizcocho «algo picado»

- Una tinaja de bizcocho

-2 tinajas de azúcar

-50 pescados secos

- 100 petates medianos «algunos comidos o rotos»

-36 gallinas

-5 gantas de romero

-2 bombones o cubillos pequeños de miel de abeja

-2 arrobas de vino de misa

-75 gantas de aceite 44

44 «Que anualmente da Su Majestad para el santo sacrificio y lámpara del Santísimo Sacramento». Datos extraídos del informe redactado por el prior del convento hospital de San Juan de Dios, Manila, 6 de abril de 1775, AGI, Filipinas, 652.

R. I., 1999, n. ${ }^{\circ} 215$ 


\section{RELACIÓN DE LAS FUNDACIONES Y OBRAS PÍAS ADMINISTRADAS POR LA REAL CASA DE LA SANTA MISERICORDIA, PARA EL MANTENIMIENTO DE LOS ENFERMOS DEL HOSPITAL DE SAN JUAN DE DIOS DE MANILA (AÑO 1775)}

D. Tomás García de Cárdenas

D. Manuel de León

D. Tomás de Andaya

Sr. Obispo González

D. Antonio Bazarte

Abad D. Juan Bautista Sidoti

Dr. D. Nicolás de la Vega

D. Manuel Martínez Lobo

D. Jose Morales

D. Domingo Bermúdez

D. José Morales

D. Pedro Basilio de la Vega

Dña. $\mathrm{M}^{\mathrm{a}}$ Joaquina Collantes

Dña. Francisca, D.Joaquín y D. Felipe Bustamante

Ntra. Señora de los Gozos

D. Francisco Carriedo y Peredo

D. Lorenzo de Reoyo
100 pesos para sustento y regalo de los enfermos. Dió el año pasado 55 pesos, 2 reales y 6 granos

400 pesos para el mismo fin. Dió el año pasado 295 pesos, 2 reales y 6 granos 100 pesos para el mismo fin. Dió el año pasado 18 pesos, 6 reales y 8 granos. 400 pesos. Dió el año pasado 182 pesos, 7 reales y 7 granos.

250 pesos (no está en estado)

240 pesos para los administradores del hospital. 100 pesos para el médico. 100 pesos para la botica y 40 para un cirujano (no se distribuyó por no estar en estado)

250 pesos (no se distribuyó por la misma razón)

50 pesos (no se distribuyó por la misma razón)

100 pesos. Se distribuyó el año pasado.

100 pesos (no se distribuye por no estar en estado)

300 pesos para el hospital y convento (no se distribuyó por no estar en estado)

500 pesos para la manutención de los enfermos y enfermas vergonzantes (no se distribuyó por la misma razón)

500 pesos para la manutención de enfermos y enfermas convalecientes (no se distribuyó por no estar en estado)

85 pesos (no se distribuye por no estar en estado )

aplica su distribución para que se le entregue al prelado del hospital, para que cumpla lo que dispusieron los fundadores (no está en corriente)

4.220 pesos para entregar al prior para la manutención de 40 camas, médico cirujano y botica, y reedificación o construcción de salas del hospital (no está en estado) 200 pesos (no distribuye por no estar en corriente $)^{45}$

45 Datos extraídos del informe firmado por el Secretario de la Real Mesa de la Santa Misericordia, don Miguel Memije, Sala del despacho de la Real Casa de la Santa Misericordia de Manila, 24 de marzo de 1775, AGI, Filipinas, 652. 
This article studies the history of the Santa Rosa Beatas' House, also called Mother Paula's, since its foundation in 1750 to its final consolidation in 1789. Along those thirty nine years the centre, born out of the generosity of a Spanish lady, confronted a series of difficulties until it finally obtained royal support and official recognition by the city of Manila.

The study is based on unpublished documentation from the Archivo General de Indias of Seville, and it aims at contributing to the knowledge of the nature and functioning of this type of communities, the history of which is still to be made.

R. I., $1999, \mathrm{n}^{\circ} 215$ 